Background Due to its topography and history, Halton, Merseyside, provides a valuable natural experiment to investigate the divide between lay and official knowledge about environment and deprivation, and how these may influence health choices and outcomes.

Methods To gain a cross-section of the local population, households in every street in each of six predefined areas received an invitation. Fifty-five semi-structured interviews were carried out to assess residents' perceptions and experiences of health, environment and lifestyle. A life history approach was taken to examine health over time, and how lifestyle choices were constructed.

Interviews were taped, transcribed, and analysed for themes using a Structuration Theory approach. Residents' viewpoints were then presented to twenty local public organisation officials, whose own perceptions were also obtained.

Results While local residents were aware of health messages, these were adopted out of personal choice, not in order to accord with perceived edicts. Residents expressed scepticism about how official knowledge was constructed, and dismay that official knowledge viewed ill-health as the result of lifestyle rather than environmental or socio-economic factors.

There was a perception that enduring deprivation was sought to be maintained in order to attract funding which would benefit officials with vested interests who lived outside the borough and could therefore afford to be unconcerned about its problems.

An illustrative quotation from a resident is: "Why kill the goose that laid the golden egg? Why get rid of poverty, deprivation and poor health when these big pots of money keep rolling in?”.

Discussion Health messages, like other forms of knowledge, may be interpreted more from the presentation and perceived motivation for issuing the message than from the content of the message. Where there is a divide between lay and official knowledge, this motivation may be seen as a means of asserting power rather than either a scientifically-based or an altruistic programme of education or information.

If lifestyles are viewed by officials as the prime factor influencing an area's health profile, this view may be interpreted by lay knowledge as a means of social control meaning that the perceived root causes of socio-economic inequality need not be tackled, and that the priority of interventions is to maintain a privileged position.

\section{P24 INDIVIDUAL FACTORS ASSOCIATED WITH SELF- REPORTED MEASURES OF COLD HOMES DURING WINTER}

${ }^{1} \mathrm{C}$ Sartini*, ${ }^{2} \mathrm{P}$ Tammes, ${ }^{2} \mathrm{~A}$ Hay, ${ }^{3}$ I Preston, ${ }^{4} \mathrm{D}$ Lasserson, ${ }^{5} \mathrm{PH}$ Whincup, ${ }^{1} S G$ Wannamethee, ${ }^{2}$ RW Morris. ${ }^{1}$ Primary care and Population Health, UCL, London, UK; ${ }^{2}$ School of Social and Community Medicine, University of Bristol, Bristol, UK; ${ }^{3}$ Household Energy Services, Centre for Sustainable Energy, Bristol, UK; ${ }^{4}$ Nuffield Department of Medicine, University of Oxford, Oxford, UK; ${ }^{5}$ Population Health Research Institute, St George's University of London, London, UK

\subsection{6/jech-2017-SSMAbstracts. 126}

Background An estimated 9000 people died during the winter 2014-2015 in England and Wales from living in a cold home. Older people are susceptible to cold, but it is unclear how to identify those who particularly find it hard to keep warm in winter. The aim of this study was to identify individual factors associated with self-reported measures of cold homes among older people.

Methods Data were from the British Regional Heart Study (BRHS) of older men, who were aged 74-95 when completing a questionnaire in 2014. This included four self-reported measures of cold housing during the previous winter (outcomes): (i) having difficulties in meeting the heating/fuel costs; (ii) staying in bed longer in order to stay warm; (iii) turning the heating off even when cold because of worries about the costs; (iv) keeping the living room comfortably warm. Individual data, including demographic characteristics, health and lifestyle factors were also collected. Cross-sectional associations between individual factors and measures of cold housing were analysed using logistic regression models.

Results Descriptive statistics showed that (i) 327 out of 1608 (20.6\%) men had difficulties in meeting the heating/fuel costs; (ii) $210(13.3 \%)$ stayed in bed longer in order to stay warm; (iii) $157(10.2 \%)$ turned heating off because of worries about the costs, and (iv) 54 (3.4\%) could not keep comfortably warm in the living room. In full adjusted logistic models, some individual factors were independently associated with the four outcomes $(p<0.05)$ : manual social class, having more financial difficulties, feeling isolated from others, and being not married. The relationship between reporting general financial difficulties and difficulties in meeting the heating/fuel costs was particularly strong (Odds Ratio $[\mathrm{OR}]=4.9$, 95\% Confidence Interval $[\mathrm{CI}] 3.9 ; 6.1)$. Also, men with mobility limitations were twice as likely to stay in bed longer in order to stay warm $(\mathrm{OR}=2.0,95 \% \mathrm{CI} 1.4 ; 2.9)$. Other individual factors, such as living in a house centrally heated and types of house insulation, as well as a proxy measure of the house energy efficiency (Energy Efficiency rating, aggregated from households within participants' Lower Super Output Area) were not related to self-reported measures of vulnerability to cold.

Conclusion Findings suggested that in older people financial difficulties and social class are key factors associated with cold housing in winter.

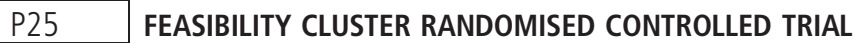 AND PROCESS EVALUATION OF AN ENVIRONMENTAL INTERVENTION IN NURSERIES AND A WEB-BASED HOME INTERVENTION TO INCREASE PHYSICAL ACTIVITY, ORAL HEALTH AND HEALTHY EATING IN CHILDREN AGED 2-4 YEARS: NAP SACC UK}

${ }^{1}$ RR Kipping*, ${ }^{1} \mathrm{R}$ Langford, ${ }^{2} \mathrm{~J}$ White, ${ }^{1} \mathrm{C}$ Metcalfe, ${ }^{3} \mathrm{~A}$ Papadaki, ${ }^{1} \mathrm{~W}$ Hollingworth, ${ }^{4} \mathrm{~L}$ Moore, ${ }^{1} \mathrm{R}$ Campbell, ${ }^{5} \mathrm{D}$ Ward, ${ }^{3} \mathrm{R}$ Jago, ${ }^{1} \mathrm{R}$ Brockman, ${ }^{1} \mathrm{~S}$ Wells, ${ }^{1} \mathrm{~A}$ Nicholson, ${ }^{1} \mathrm{~J}$ Collingwood. 'Social and Community Medicine, University of Bristol, Bristol, UK; ${ }^{2}$ School of Medicine, Cardiff University, Cardiff, UK; ${ }^{3}$ School of Policy Studies, University of Bristol, Bristol, UK; ${ }^{4} \mathrm{MRC/CSO}$ Social and Public Health Sciences Unit, University of Glasgow, Glasgow, UK; ${ }^{5}$ Gillings School of Global Public Health, University of North Carolina at Chapel Hill, North Carolina, USA

\subsection{6/jech-2017-SSMAbstracts. 127}

Background Systematic reviews have identified the lack of intervention studies to prevent obesity in young children. Most 3 year old children in the UK attend formal childcare, and the Government plans to extend free childcare to 30 hours per week for 3 and 4 year olds; therefore these settings present an opportunity to improve health. The Nutrition and Physical Activity Self Assessment for Childcare (NAP SACC) programme aims to improve child nutrition and 